This is a pre-print of Steffen Ducheyne (2011), Newton on action at a distance and the cause of gravity, Studies in History and Philosophy of Science, Part A, vol. 42(1), pp. 154-159. It is not meant to replace the original.

\title{
Newton on action at a distance and the cause of gravity
}

\author{
Steffen Ducheyne
}

Centre for Logic and Philosophy of Science, Ghent University, Blandijnberg 2, Ghent, Belgium

E-mail address: steffen.ducheyne@ugent.be

\section{Abstract}

In this discussion paper, I seek to challenge Hylarie Kochiras' recent claims on Newton's attitude towards action at a distance, which will be presented in section 1 . In doing so, I shall include the positions of Andrew Janiak and John Henry in my discussion and present my own tackle on the matter (section 2). Additionally, I seek to strengthen Kochiras' argument that Newton sought to explain the cause of gravity in terms of secondary causation (section 3). I also provide some specification on what Kochiras calls 'Newton's substance counting problem' (section 4). In conclusion, I suggest a historical correction (section 5).

Keywords

Isaac Newton (1642-1727), action at a distance, cause of gravity, fourth letter to Bentley (25 February 1692/3)

\section{Kochiras' Claims on Action at a Distance}

The Principia clearly entails the possibility of action at a distance. But did Newton accept this possibility? In the Principia, Newton had shown that gravity acts, not mechanically, i.e. not in proportion to the surfaces of bodies on which it acts "as mechanical causes are wont to do" (Newton, 1999 [1726], p. 943), but in proportion to the quantify of solid matter (see the Corollaries to Proposition VI of Book III of the Principia in ibid., pp. 809-810 and the Scholium to Proposition LIII in Book II in ibid., pp. 789-790). Moreover, in these Corollaries he had concluded that the celestial regions contain large voids (see also Query 28 in Newton, 1979 [1730], p. 365, p. 368). In the General Scholium, this point was rendered more explicit: "All these regular motions do not have their origin in mechanical causes, since comets go freely in very eccentric orbits and into all parts of the heavens" (Newton, 1999 [1726], p. 940). Newton had established that gravity cannot be produced by the direct contact of 
material bodies and, consequently, he had shown that whatever causes gravity does so in a non-mechanical or immaterial way. ${ }^{1}$ A standard mechanical ether or vortex was shown to be inconsistent with astronomical observation. Only an extremely rarified material ether could be rendered consistent with the results harvested in the Principia. While, as will be made clear in the discussion in subsection 2.1, Newton at some point entertained the possibility of such extremely rarified mechanical ether, by 1694 he had definitely abandoned this option for good.

In a recent paper in this journal, Hylarie Kochiras seeks to chart the complex interaction between Newton's empiricism and his inclination towards certain metaphysical and rationalist principles (Kochiras, 2009, p. 268). One of the metaphysical principles Newton seems to endorse, according to Kochiras, is "the Scholastic maxim that matter cannot act where it is not" (ibid., p. 275). Accordingly, when she discusses Newton's fourth letter to Richard Bentley (25 February 1692/3), she concludes: "Here Newton appears to affirm the Scholastic metaphysical principle: matter cannot act where it is not" (ibid., p. 268). The key passage from Newton's fourth letter to Bentley reads as follows:

Tis inconceivable, that inanimate brute Matter, should (without ye mediation of something else wch is not material), operate upon \& affect other matter wthout mutual contact; as it must if gravitation in the sense of Epicurus, be essential \& inherent in it. And this is one reason why I desired you not to ascribe innate gravity to me. That gravity should be innate inherent \& essential to matter so yt one body may act upon another at a distance through a vacuum wthout the mediation of any thing else \& by $\&$ through wch their action and force may be conveyed from one to another is to me such an absurdity that I beleive no man who has in philosophical matters any competent faculty of thinking can ever fall into it. Gravity must be caused by an agent acting constantly according to certain laws, but whether this agent be material of immaterial is a question I left to ye consideration of my readers. (Newton, 1959-1977, III, pp. 253-245)

The meaning of this important passage will be discussed in subsection 2.1. In the accompanying footnote 5, Kochiras states, in reply to correspondence with John Henry, ${ }^{2}$ that "interpreting Newton as denying action at a distance by no means forces me to the view that he penned the first and last sentences in distraction" (Kochiras, 2009, p. 268). "For", she continues in the same footnote, "as I read them, Newton states his own view in the first sentence [to wit, "Tis inconceivable, that inanimate brute Matter, should (without ye mediation of something else wch is not material), operate upon \& affect other matter wthout mutual contact; as it must if gravitation in the sense of Epicurus, be essential \& inherent in it."], while in the last [to wit: "Gravity must be caused by an agent acting constantly according to certain laws, but whether this agent be material of immaterial is a question I left to ye consideration of my readers."'] he describes what he did in the Principia, which was to refrain from stating his own view."

Moreover, in footnote 50 (Kochiras, 2009, p. 273 [italics added]), Kochiras notes: 
The question of whether Newton allowed action at a distance is of course the focus of debate. The extreme positions are occupied by John Henry (1994) and Andrew Janiak (2007, 2008). Henry argues that Newton fully accepted action at a distance by accepting active powers as inessential powers of matter, superadded by God. In support of this interpretation, he takes Newton's reference to Epicurus, in the above-quoted letter to Bentley, to be highly significant; he reads Newton as rejecting only the Epicurean notion that gravity is essential to matter. Accordingly, Henry reads Newton's remark that gravitation requires 'the mediation of something else which is not material' to refer to God's mediation between the way that matter is essentially, and the way that God actually created it, by superadding active powers. For Henry, the opening of Query 31 is then a straightforward assertion that material particles do possess active powers that enable them to act distantly. Newton's qualifying remarks there and in the General Scholium, to the effect that he does not know gravity's cause, should not be understood to mean that he denied active powers to matter or denied action at a distance. He rather means to say that he simply does not know which sort of matter bears these active powers-ordinary matter, or the matter of the aether. In further support of his position, Henry points to Bentley and Locke as Newton's spokesmen, for both accepted gravity as a superadded active power of matter. (While I cannot fully engage with Henry's argument here, I have argued that the thesis of superaddition cannot easily be squared with Newton's empiricism, and, when Newton speaks of mediation, contextual remarks indicate that he has spatial mediation in mind. As for Newton's disavowal of knowing gravity's cause, one difficulty I see in Henry's explanation is that the notion of a material aether is quite problematic; as noted subsequently, it threatens regress.)

With respect to Newton's Letter to Bentley on 25 February 1692/3, Kochiras introduces two connected assumptions, scilicet she assumes (1) that in the first and final sentence Newton is addressing the same topic, i.e. she assumes that the issue of mediation, as introduced in the first sentence, is the same as the issue of agency, introduced in the final sentence and (2) that by that time Newton had already embraced an immaterial explanation of gravity. ${ }^{3}$

In 2.1, I shall argue that both assumptions are debatable and historically untenable. It will be argued that Kochiras' interpretation of Newton's letter to Bentley on 25 February 1692/3 is based on a selective reading of Newton's corpus and that her account of Newton's views on action at a distance is mistaken. Note, by the way, that Kochiras' discussion of Newton's views on action at a distance is essentially based on essentially two fragments of Newton's corpus: Newton's fourth letter to Bentley (1692/3) and the General Scholium (1713). I shall also contextualise Newton's views on action at a distance by taking into account several other historical documents. On the basis of this, I shall defend a more adequate position on the issue at stake (see subsection 2.2). In her paper, Kochiras steers clear of showing what a proper account on the matter should look like and, moreover, by her reply to Henry's she tends to obscure the discussion, rather than to enlighten it. 


\section{Newton on Action at a Distance}

I start my discussion by pointing out that a thorough contextualisation of all relevant material related to action at a distance (including Newton's manuscripts) is currently lacking in Kochiras' (and Janiak's) interpretation is. By taking additional resources into account, a more subtle and plausible reconstruction of Newton's views on the matter is within reach, or so I shall argue. A solid interpretation of Newton's fourth letter to Bentley cannot be established without proper contextualisation of the documents referred to - I therefore strongly suggest that in future discussions of Newton's attitude towards action at a distance due consideration is given to them.

\subsection{Evidence suggesting that (1) and (2) are not unproblematic}

According to Kochiras, Newton states his own view in the first sentence of his fourth letter to Bentley ("Tis inconceivable, that inanimate brute Matter, should (without ye mediation of something else wch is not material), operate upon \& affect other matter wthout mutual contact [...]"), while in the last sentence ("[...] but whether this agent be material of immaterial is a question I left to ye consideration of my readers.") he describes what he did in the Principia, which was to refrain from stating his own view. In what follows, I shall develop a more natural way to interpret the key passage of Newton's fourth letter to Bentley.

Let me begin by pointing out that, when Newton questioned the Cartesian vortex cosmology, he was already in his forties. Before De motu Newton was inclined to explain gravitation in mechanical terms. In 1680-1681, when drafting up some propositions on cometary motion, Newton still seemed to think along the lines of a vortex cosmology (cf.: " 2 . Materiam coelorum fluidam esse. 3. Materiam $\downarrow$ coelorum $\downarrow$ illam circa centrum systematis cosmici secundum cursum Planetarum gyrare." (CUL Add. Ms. 3965, fo. $\left.613^{\mathrm{r}}\right)$ ). ${ }^{4}$ Consistent with this, in his 1680/1 correspondence with Thomas Burnet, Newton claimed that vortices offered a sensible explanation of gravity and he relied on centrifugal forces for the explanation of the celestial motions (Newton, 1959-1977, II, pp. 319-334). In De motu and the Principia all this was to change dramatically.

When Fatio De Duillier was working on his De la cause de la pesanteur (1690) (De Duillier, 1948-9), in which he introduced a mechanical ether to explain gravitation, he pointed out in a letter to Huygens on 24 February 1689/90, that "Je marquerai seulement en passant que Mr. Newton trouve que l'experience s'accorde avec cette pensée" (Newton, 1959-1977, III, p. 69). ${ }^{5}$ Later, in a memorandum by David Gregory on 28 December 1691, however, it is reported that "Mr Newton and Mr Hally [sic] laugh at Mr Fatios manner of explaining gravity" (ibid., III, p. 191). In a letter to Leibniz on 30 March 1694, De Duillier wrote that "Monsr. Newton est encore indeterminé entre ces deux sentiments. Le premier que la cause de la de la Pesanteur soit inherente dans la matiére par une Loi immediate du Createur de l'Univers: et l'autre que la Pesanteur soit produite par la cause Mécanique que j'en ai trouvée" (ibid., III, p. 309). These sources indicate that Newton between February 
1689/90 and March 1694 wavered between a mechanical and immaterial explanation of gravity. We do know, however, with certainty that from May 1694, i.e. the time when David Gregory saw Newton's Classical Scholia, Newton no longer considered a mechanical agent as a plausible candidate to explain gravitation, for in the Classical Scholia he posited an immaterial agent as the cause of gravity (see section 3).

The data gathered above shows two things: first, before May 1694 Newton wavered between a mechanical and immaterial agent or explanation for gravitation; secondly, only after May 1694 did Newton commit himself to an immaterial agent to account for gravitation. Therefore, in 1692/3 Newton had not yet made his mind up on the matter and he genuinely doubted whether the agent producing gravitation is material or immaterial. It was only by 1694 that Newton made up his mind and opted for an immaterial agent. Thereafter, he consistently clung to an immaterial agent as explanation of gravitation. To suggest, therefore, that in his fourth letter to Bentley Newton was communicating his own (immaterial) candidate for the explanation of gravity, is thus highly implausible and contrary to the historical records. Newton was not contrasting his own candidate and "what he did in the Principia": he was reporting on two causes of gravity - one mechanical, the other immaterial - which he considered as equally plausible at that time. Nothing of the above context is mentioned in Kochiras, 2009 (nor in Janiak, 2007 and 2008, for that matter).

That Newton distinguishes between the issue of mediation, as introduced in the first sentence, and the issue of agency, as introduced in the final sentence, is suggested by the context of Newton's letters to Bentley - a context which is simply absent from Kochiras' discussion. Note that the sentence immediately preceding the key passage from Newton's letter to Bentley on 25 February 1692/3, which I have quoted in section 1, is the following: "The last clause of your second Position I like very well." (Newton, 1959-1977, III, p. 253). The clause from Bentley's letter on 18 February 1692/3 to which Newton refers to is:

[Sir, I make account, yt your courteous suggestion by your Last, yt a Chaos is inconsistent with ye Hypothesis of innate Gravity, is included in this paragraph of mine.] and again, tis inconceivable, yt inanimate brute matter should (without a divine impression) operate upon \& affect other matter without mutual contact: as it must be, if gravitation be essential and inherent in it." (ibid., III, p. 249 [italics added]).

Therefore, it seems that with the first occurrence of "mediation" Newton was referring to God's activity and intervention in rerum naturae (hence his words: "without ye mediation of something else wch is not material"). Let me elaborate this point. First of all, I strongly object to Kochiras' contention that John Henry "reads Newton as rejecting only the Epicurean notion that gravity is essential to matter." Henry does not "read" this interpretation into the text; it is what the text itself dictates: "Tis inconceivable, that inanimate brute Matter, should (without ye mediation of something else wch is not material), operate upon \& affect other matter wthout mutual contact; as it must if gravitation in the sense of Epicurus, be essential \& inherent in it. And this is one reason why I desired you not to ascribe innate gravity to me." [italics added]. On the Epicurean account, gravity is an essential and inherent property of 
bodies. This means that, according to the Epicurean account, "inanimate brute Matter" has the capacity of attracting, by its own nature, other matter across a vacuum, i.e. "without the mediation of something else." This implies that matter is not passive and that it can activate other matter without any external principles being required - both implications were equally unacceptable for Newton. It is this Epicurean view that Newton considered as "an absurdity." Newton emphasized that gravitational interaction required the activity of external or external causes and forces. Bodies are passive and are moved by activating principles: "[f]or we meet very little Motion in the World, besides what is owing to these active Principles" (Newton, 1979 [1730], p. 399). The Epicurean view of gravity was untenable for Newton to accept since it would imply that matter itself was self-propelling and self-activating. This was the reason why Newton rejected Epicurean gravity. By contrast, Newton sought to establish (1) that Epicurean attraction would result in a chaotic world and, correspondingly, that the elegance and harmony of the solar system could only be guaranteed by "the design and dominion [consilio \& dominio] of an intelligent and powerful being" (Newton, 1999 [1726], p. 940) and (2) that matter and motion is somehow dependent on God. In order to accomplish the latter, Newton argued that God regulates the natural world by means of certain activating principles which he had installed and maintains. In the drafts for the first edition of The Opticks, Newton would again raise this concern:

$\mathrm{Qu} 23$. By what means do they bodies act on one another at a distance. The ancient Philosophers who held Atoms \& Vacuum attributed gravity to Atoms without telling us the means unless perhaps in figures: as by calling God Harmony \& comparing $\downarrow$ representing $\downarrow$ him \& matter by the God Pan $\&$ his Pipe, or by calling the Sun the prison of Jupiter because he keeps the Planets in their orbs. Whence it seems to have been an ancient opinion that matter depends upon a Deity for its $\downarrow$ laws of $\downarrow$ motion as well as for its existence. The Cartesians make God the author of all motion \& its as reasonable to make him the author of the laws of motion. Matter is a passive principle \& cannot move it self. It continues in its state of moving or resting unless disturbed. It receives motion proportional to the force impressing it. And resists as much as it is resisted. These are passive laws \& to affirm that there are no other [laws] is to speak against experience. (CUL Add. Ms. 3970, f. 619 ${ }^{\mathrm{r}}$ [ca. 1700-1704; italics added]) ${ }^{7}$

In sum, on 25 February 1692/3, Newton was convinced that the intervention of God, who is surely not material, was somehow required for the production gravitational interactions between bodies. However, at that point he was undecided as to whether the agent or intermediary producing gravity was material or not. It seems therefore that Newton was discussing two separate issues after all.

\subsection{Newton on action at a distance: a new interpretation}

Kochiras (and Janiak) seem to accept the non sequitur that by rejecting John Henry's super-addition thesis they have succeeded in defusing all points raised by 
Henry. Note that I do not commit - nor do I need to - myself to Henry's superaddition thesis, to which Kochiras objects in section 4 (Kochiras, 2009, pp. 272-276). ${ }^{8}$ Henry has, however, adequately noted that the ethers Newton introduced to account for gravitation were not mechanical since they "consisted of particles held apart from one another, and from particles to other matter, by repulsive forces operating between them" (Henry, 1994, p. 123) and that "the aether theories were not intended to be a way of avoiding actions at a distance" (ibid., p. 135). These points are well taken. ${ }^{10}$ Moreover, in the context of his optical research Newton openly allowed the possibility of action at a distance (Newton, 1979 [1730], p. 339, pp. 370-371, pp. 375376; CUL Add. Ms. 3970, fos. $252^{\mathrm{r}}-254^{\mathrm{r}}$, fo. $257^{\mathrm{r}}$, fo. $273^{\mathrm{r}}$, fo. $291^{\mathrm{r}}$ [ca. $1700-1704$ ]).

The interpretation of Newton's view on action at a distance I shall now defend takes into account the two important points made by Henry, without endorsing his super-addition thesis (see additionally, the discussion in Ducheyne, 2009, pp. 237239). Newton denied that matter could act at a distance according to its own nature (because this would imply that matter would be innately self-acting, an option unacceptable for Newton); however, Newton endorsed action at a distance for the secondary mechanism producing gravity, because he postulated a very subtle "elastick" ether, i.e. an extremely rare medium endowed with strong inter-particular repulsive forces," as an explanation or cause of gravity. Newton was, of course, clearly aware that the elastic ether was conjectural and not a demonstrated truth, for in the Advertisement added to the 1717 edition of The Opticks he observed that he was "not yet satisfied about it [i.e. his attribution of the cause of gravity] for want of Experiments" (Newton, 1979 [1730], cxxiii). ${ }^{11}$ The point is that he was willing to entertain this possibility and even make it public. Newton's elastic ether consisted of repellent particles acting at a distance. In a nutshell: Newton rejected action at a distance at a macro-level but accepted it at a micro-level. This seems to be supported by the Advertisement to the 1717 edition of The Opticks: "And to shew that I do not take Gravity for an essential Property of Bodies [i.e. to show that "inanimate brute Matter" does not have the capacity of attracting, by its own nature, other matter across a vacuum], I have added one Question concerning its Cause [i.e. an attribution of the cause of gravity which posits an elastic ether and which supposes inter-particular repulsive forces between its constituting particles acting at a distance], chusing to propose it by way of a Question" (Newton, 1979 [1730], cxxiii). Newton did not have any a priori objections against actio in distans. ${ }^{12}$ In a nutshell, Newton did not reject actio in distans per se, nor did he deem it intrinsically problematic. Newton could not accept of action at a distance at a macro-level, for that would entail the approval of Epicurean attraction. However, this does not mean that he found the notion of actio in distans intrinsically problematic, for in The Opticks he postulated a non-mechanical intermediary (micro-level) acting at a distance to account for the explanation or cause of gravity. The reason why Newton was happy to introduce, despite the "conceptual problems" involved by doing so (cf. Kochiras, 2009, p. 277), an immaterial cause of gravity, in casu an "elastick ether" which supposed action at a distance among its particles, was that he considered it as a viable means to avoid the self-propelling activity of matter and to account for the non-mechanical nature of gravitational effects as suggested by empirical evidence. This suggests a rather 
different interaction between Newton's metaphysical and empirical considerations than the one suggested by Kochiras.

\section{Newton on the Cause of Gravity and Secondary Causation}

Despite my comments in the previous section, I am in full agreement with Kochiras' claim that Newton consistently tried to explain gravity in terms of secondary causation (Kochiras, 2009, p. 272). However, I think that her argumentation can be made stronger. For, as it stands, many readers might argue that James E. McGuire and Piyo M. Rattansi, in their locus classicus on the Classical Scholia, have argued otherwise, namely that Newton did at some point explain gravity by referring to direct divine intervention. ${ }^{13}$ In a nutshell, their view is that:

The central purpose of the 'classical' scholia was to support the doctrine of universal gravitation as developed in these Propositions, and to enquire into its nature as a cosmic force. This doctrine is shown by Newton to be identifiable in the writings of the ancients. As will become clear, he is not using this historical evidence in a random fashion, or merely for literary ornamentation. Rather the evidence is used in a serious and systematic fashion, as support for, and justification of, the components of Newton's theory of matter, space and gravitation. The evidence is used to establish four basic theses, which correspond to the matter of Proposition IV to IX. These are, that there was an ancient knowledge of the truth of the following four principles: that matter is atomic in structure and moves by gravity through void space; that gravitational force acts universally; that gravity diminishes in the ratio of the inverse square of the distances between bodies; and that the true cause of gravity is the direct action of God. (McGuire and Rattansi, 1966, pp. 111-112 [italics added])

Therefore, we need to adduce appropriate reasons to reject McGuire and Rattansi's interpretation of the Classical Scholia. First of all, it should be noted that claiming that God directly causes gravity is not the same as claiming that gravity depends on the will of God - for the latter leaves open the possibility of an intermediary. That Newton made the latter claim in the Classical Scholia is obvious. ${ }^{14}$ To the best of my knowledge, there is no positive and direct evidence to suggest that Newton entertained the former. On Royal Society, Gregory Ms. 247, fo. $14^{\mathrm{v}}$, Newton noted that the Ancients distinguished between god and the spirit producing gravity: "Hunc spiritum aliqui a Deo summo distinxerunt \& animam mundi vocarunt," which leaves open the possibility of an intermediary (cf. Dobbs, 1991, pp. 36-37, to which Kochiras does not refer to). ${ }^{15}$ The same caveat applies to Newton's later assertion (ca. 1706) that "matter depends upon a Deity for its $\downarrow$ laws of $\downarrow$ motion as well as for its existence" (CUL Add. Ms. 3970, fo. 619 ): again, Newton did not literally and positively state that gravitation is produced directly by divine intervention. 


\title{
4. On 'Newton's Substance Counting Problem'
}

\author{
follows: \\ According to Kochiras, Newton's 'Substance Counting Problem' arises as
}

Since his ontology includes spatially extended immaterial substances as well as matter, and since these different sorts of extended substances might be able to occupy the same place at the same time, it is not clear how many substances should be inferred from the properties perceived in a given region of space. (Kochiras, 2009, pp. 278-279)

This problem, however, only pertains to universal properties, i.e. properties that cannot be intended and remitted, such as gravity. Gravity cannot be remitted and intended at equal distances from an attracting body. Consider, by contrast, the case of magnetism, which Newton considered as being produced by a short-range attractive force that can be intended or remitted (CUL Add. Ms. 3970, fo. 258 ${ }^{\mathrm{r}}$ [ca. 1700-1704]). If we magnetically charge a piece of metal and if we smash it with great force against the ground, the magnetic properties will have gone lost. Likewise, if we heat a magnetized piece of metal, its magnetic properties will have vanished. In this case, we can contrast the effects of a de-magnetized and magnetized piece of metal. ${ }^{16}$

\section{Erratum}

Finally, I cannot refrain from making a historical correction. In footnote 11 Kochiras claims that in De gravitatione (CUL Add. Ms. 4003) Newton "does not yet have the concept of mass as distinguished from weight" (Kochiras, 2009, p. 269). This claim is inaccurate since Newton explicitly referred to quantity of matter in $D e$ gravitatione when reporting on his own pendulum experiments. Newton began, as follows:

For if the aether were a corporeal fluid entirely without vacuous pores, however subtle its parts are made by division, it would be as dense as any other fluid, and it would yield to the motion of passing bodies with no less inertia; indeed with a much greater inertia if the projectile were porous, because then the aether would enter into its internal pores, and encounter and resist not only the whole of its external surface, but also the surface of all the internal parts. Since the resistance of the aether is on the contrary so small when compared with the resistance of quicksilver as to be over ten or a hundred thousand times less, there is all the more reason for thinking that by far the largest part of the aetherial space is empty, scattered between the aetherial particles. The same may also be conjectured from the various gravities of these fluids, for the descend of heavy bodies and the oscillations of pendulum show that these are in proportion to their densities, or as the quantities of matter contained in equal spaces. But this is not the place to go into this. (Janiak, 2004, p. 35). 
Newton suggested that the resistance of the subtle ether is very small, namely 10.000 or 100.000 times less ("decies vel centies mille vicibus minor" (CUL Add. Ms. 4003, p. $31\left(=\right.$ fo. $\left.19^{\mathrm{r}}\right)$ ) than quicksilver. Moreover, he noted that if such corporeal ether as described above would exist then it would act on both the whole external surface and on each of the surfaces of its internal parts ("non modo totius externa $\downarrow$ $\downarrow$ m superficiem $\downarrow i \downarrow$ sed et omnium internarum partium superficiebus occurreret et impedimento esset" (CUL Add. Ms. 4003, p. $30\left(=\right.$ fo. $\left.18^{v}\right)$ ). However, Newton's experiments with pendulums had shown that the resistance exerted on oscillating bodies is negligible, which suggests oscillating bodies describe equal spaces in equal times. ${ }^{17}$ Therefore, he noted that the gravities of oscillating bodies are as their "densities" or quantity of matter ("ut eorum densitas $\downarrow$ tes $\downarrow$ sive ut quantitas $\downarrow$ tes $\downarrow$ materiæ" (CUL Add. Ms. 4003, p. $31\left(=\right.$ fo. $\left.\left.19^{\mathrm{r}}\right)\right)^{18}$ - thereby implying that he did conceptually distinguish between weight and mass in De gravitatione. Moreover, it has been pointed out that these very fragments contain crucial clues for dating CUL Add. Ms. 4003, as we have it (Dobbs, 1991, chapter 5, esp. pp. 142-143; Mandelbrote, 2001, pp. 99-100).

\section{General Scholium}

By now, I hope to have made it plausible that Kochiras' claims on Newton and action at a distance are debatable, to say the very least. It is unfortunate that an appropriate contextualisation of Newton's views on action at a distance is simply absent from her paper. Because of this, her reading is selective and ultimately biased. As Newton himself might have suggested, a justified principle should be consistent will all evidence. I hope that, in future work on Newton and action at a distance, the vast bulk of Newton's corpus will be part of that evidence.

\section{Acknowledgements}

The author's research is funded by a Postdoctoral Fellowship of the Research Foundation - Flanders (FWO). The author is much obliged to the Provosts and Syndics of Cambridge University Library and the Library and Archives of The Royal Society for permission to quote the material in their care. The author is indebted to the editors and the anonymous referee for useful comments and suggestions.

\section{References}

De Duillier, F.N. (1948-9 [1690]). De la cause de la pesanteur. Mémoire de Nicolas Fatio de Duillier présenté à la Royal Society le 26 février 1690 (B. Gagnebin, ed.). Notes and Records of the Royal Society of London, 6, 105-160.

Dobbs, B.J.T. (1991). The Janus Faces of Genius, The role of alchemy in Newton's thought. Cambridge: Cambridge University Press. 
Ducheyne S. (2005). Newton's Training in the Aristotelian Textbook Tradition: From Effects to Causes and Back, History of Science, 43, 217-237.

Ducheyne S. (2006). The General Scholium: Some Notes on Newton's Published and Unpublished Endeavours, Lias: Sources and Documents Relating to the Early Modern History of Ideas, 33, 223-274.

Ducheyne S. (2009). Understanding (in) Newton's Argument for Universal Gravitation, Journal for General Philosophy of Science, 40, 227-258.

Henry, J. (1994). "Pray do not Ascribe that Notion to Me": God and Newton's Gravity. In: J.E. Force and R.H. Popkin (Eds.). The Books of Nature and Scripture: Recent Essays on Natural Philosophy, Theology and Biblical Criticism in the Netherlands of Spinoza's Time and the British Isles of Newton's Time. Dordrecht: Kluwer, 123-147.

Henry, J. (2007). Isaac Newton y el Problema de la Acción a Distancia. Estudios de filosofía, $35,189-226$.

Janiak, A. (ed.) (2004). Isaac Newton, Philosophical Writings. Cambridge: Cambridge University Press.

Janiak, A. (2007). Newton and the Reality of Force. Journal for the History of Philosophy, 45, $127-147$.

Janiak, A. (2008). Newton as Philosopher. Cambridge Cambridge University Press.

Kochiras, H. (2009). Gravity and Newton's Substance Counting Problem. Studies in History and Philosophy of Science, 40A, 267-280.

Mandelbrote, S. (2001). Footprints of the Lion: Isaac Newton at Work, Exhibition at Cambridge University Library, 9 October 2001-23 March 2002. Cambridge: Cambridge University Library.

McGuire, J.E. and Rattansi, P.M. (1966). Newton and the 'Pipes of Pan'. Notes and Records of the Royal Society of London, 21, 108-143

McMullin, E.V. (1978). Newton on Matter and Activity. Notre Dame: University of Notre Dame Press.

Newton, I. (1959-1977). The Correspondence of Isaac Newton (7 vols.). Edited by H.W. Turnbull, J.F. Scott, A.R. Hall, and L. Tilling. Cambridge: Cambridge University Press.

Newton, I. (1979 [1730]). Opticks or a Treatise of Reflections, Refractions, Inflections and Colours of Light. New York: Dover.

Newton, I. (1999 [1726]). The Principia, Mathematical Principles of Natural Philosophy (I.B. Cohen \& A. Whitman, Trans.). Berkeley: University of California Press.

Ruffner, J.A. (2000). Newton's Propositions on Comets: Steps in Transition, 1681-84. Archive for History of Exact Sciences, 54, 259-277.

Whiteside, D.T. (Ed.) (1967-1981). The Mathematical Papers of Isaac Newton (8 vols.). Cambridge: Cambridge University Press.

${ }^{1}$ In Query 28, Newton wrote that gravity is produced by "some other Cause than dense Matter" (Newton (1979 [1730]), p. 369).

${ }^{2}$ Here Henry is reported saying: "The standard reading of the passage in the letter to Bentley makes Newton seem at best distracted and at worst an idiot for saying that the mediating agent of gravity is immaterial and then a couple of sentences later [saying] he doesn't know whether the agent is material or immaterial. This is a problem for the standard reading ... but it isn't a problem for me because I say that he first claims that an immaterial God gives matter the power to attract other matter, and that a couple of sentences later he is no longer talking about God but is talking about 
the power that God gave to the matter - that power, or the way it operates, might be either material or immaterial."

${ }^{3}$ On Newton and causal explanation see Ducheyne (2005), (2006) and (2009), pp. 229-237.

${ }^{4}$ These propositions are discussed in detail in: Ruffner (2000).

${ }^{5}$ On CUL Add. Ms. 4005.6, fo. $28^{\mathrm{r}}$ [ca. 1690-1693], Newton wrote in a rather neutral tone: "Errant igitur qui corporum particulas minimas eөrpe ad modum particularum arenæ aut lapidum coacervatorum confertim jungunt. Si particulæ aliquæ tam dense constipentur, causa gravitans desinet esse proportionalis materiæ. Excogitandæ sunt aliæ particulatum texturæ quibus interstitia earum reddantur amplissima. Et hæ sunt necessariæ conditiones Hypotheseos per quam gravitas explicetur mechanicè. Hujus autem generis Hypothesis est unica per quam gravitas explicari potest, eamque Geometra ingeniosissimus D.N. Fatio primus excogitavit.". By ca. 1716-18 Newton's tone had changed drastically: "Mechanicam gravitatis causam D. Fatio olim excogitavit, sed veram esse non probavit. Hypothesis erat, \& in Philosophia experimentali hypotheses non considerantur." (CUL Add. Ms. 9597.2.11, fo. $\left.3^{\mathrm{r}}\right)$.

${ }^{6}$ John Henry (1994) is surely to be given the credit for emphasizing the Epicurean position to which Newton is reacting against.

${ }^{7}$ A relevant variant is: "What is it by means of $w^{\text {ch }}$ bodies act on one another at a distance. And To what Agent did the Ancients attribute the gravity of their atoms. Or what did they mean [...] by calling God an harmony \& comparing him \& matter [...] to $\mathrm{y}^{\mathrm{e}}$ God Pan \& his Pipe." (CUL Add. Ms. 3970, f. $291^{\mathrm{r}}$ [ca. 1700-1704; italics added]). Convention for my transcriptions: arrows pointing downwards $(\downarrow \ldots \downarrow)$ indicate that the text in between them was inserted above Newton's original interlineation. Arrows pointing upwards $(\uparrow \ldots \uparrow)$ indicate that the text in between them was inserted under Newton's original inter-lineation. Unless stated otherwise, all other text-editorial features are as in the original.

${ }^{8}$ The direct evidence in support of Henry's super-addition thesis is rather slender. Indirect evidence for the super-addition thesis is to be found in De Duillier testimony to Leibniz on 30 March 1694 (see previous subsection). If Newton had actually endorsed this option, it would have been for a very brief period of time.

${ }^{9}$ This observation is correct, for if Newton thought otherwise we would have to accept the conclusion that Newton tried to explain away action at a distance at the macro-level by reintroducing it at the micro-level.

${ }^{10}$ In Janiak (2007), where Janiak does not refer to Henry's work, it is claimed that Newton rejected action at a distance without further qualification (cf. Janiak 
(2008), p. 54, p. 172; cf. ibid., p. 53, footnote 5). In Janiak 2008 Henry's views are too quickly dismissed on the basis of an excerpt wherein Henry incorrectly wrote that gravity is "a superadded inherent property" (Henry (1994), p. 141). In any case, Henry's super-addition thesis should not detract us from the important points he made: that the ether theories did not originate in Newton's dissatisfaction with action at a distance per se, and that Newton accepted action at a distance in his optical work and in his work on the cause of gravity. In the subsequent discussion, Janiak nowhere takes these two points into account (Janiak (2008), pp. 53-65).

${ }^{11}$ Newton's account of gravitation as being produced by "the elastick force" of mutually repellent minute particles occurs in Query 21 (Newton (1979 [1730]), pp. 350-352). If Newton's attribution were correct than gravitational "attraction" would result from the repellent forces of the elastic medium in which the celestial bodies are situated (cf. ibid., p. 376).

12 This conclusion was reached earlier in McMullin (1978), p. 144, footnote 13 and p. 151 , footnote 210 .

${ }^{13}$ In her article, Kochiras does not refer to McGuire and Rattansi (1966).

${ }^{14}$ For in Royal Society, Gregory Ms. 247, fo. $14^{\mathrm{r}}$, Newton wrote: "Solum enim ens intelligens vi voluntatis suæ $\downarrow$ secundum intellectuales rerum ideas $\downarrow$ propter causes finales agendo varietatem rerum introducere potuit."

${ }^{15}$ Dobbs notes that Newton's claiming that God's directly causing gravity would have been utterly non-explanatory (Dobbs (1991), pp. 197-198. Furthermore, the claim that gravity is produced directly by God would have caused some theological uneasiness in Newton's thinking (ibid., Chapter 7), for Newton endorsed the idea that "God made \& governs the world by his Agents" (CUL Add. Ms. 3965, fo. $368^{\mathrm{v}}$ [post1713]).

${ }^{16}$ On gravitational effects Kochiras remarks: "If it is not possible to remove immaterial substances or to determine whether or not they are present, it is not possible to know whether gravitational effects would occur in their absence." (Kochiras (2009), p. 278).

${ }^{17}$ Later, in Proposition XXIV of Book I of the Principia, Newton started with an application of the second law of motion: $v::\left(F_{\mathrm{m}} \times t\right) / \mathrm{m}$. If the pendulums are of the same length, the motive forces are as the weights: $F_{\mathrm{m} 1} / F_{\mathrm{m} 2}:: W_{1} / W_{2}$. Then the velocities in the corresponding parts of the oscillations will be to one another as the motive forces and the whole times directly and the quantities of matter inversely: $v_{1} / v_{2}::\left(F_{\mathrm{m} 1}\right.$ $\left.\times t_{1} \times m_{2}\right) /\left(F_{\mathrm{m} 2} \times t_{2} \times m_{1}\right)$ or $m_{1} / m_{2}::\left(F_{\mathrm{m} 1} \times t_{1} \times v_{2}\right) /\left(F_{\mathrm{m} 2} \times t_{2} \times v_{1}\right)$. Since the velocities are inversely as the squares of the times and we assume that the times are equal: $m_{1} / m_{2}::\left(F_{\mathrm{m} 1} \times t_{1}^{2}\right) /\left(F_{\mathrm{m} 2} \times t_{2}^{2}\right)::\left(W_{1} \times t_{1}^{2}\right) /\left(W_{2} \times t_{2}^{2}\right)$ or $m_{1} / m_{2}:: F_{\mathrm{m} 1} / F_{\mathrm{m} 2}:: W_{1} / W_{2}$. Hence, if the times are equal, the quantities of matter will be as weights. 
${ }^{18}$ No further empirical data was provided. Newton's first uncontroversially dateable introduction of "quantitas materiae" is in the initial revise of De Motu (Whiteside (1967-1981), VI, p. 92). 